\title{
Viver em ritmo menos acelerado: Sobre tempos de pausa e o cuidado com a vida na Bíblia
}

\author{
Living at a less accelerated pace: About break times and \\ care for life in the Bible \\ HAROLDO REIMER ${ }^{a}$ \\ IVONI RICHTER REIMER
}

\section{Resumo}

O contexto da pandemia do Sars-Covid-19 é o motivador hermenêutico do presente artigo, que busca colocar em foco alguns textos da Bíblia que propõem a observância de tempos de pausa em meio aos ritmos de trabalho. São fragmentos textuais que se originaram ao longo da história dos antigos hebreus, propondo a heterotopia de que em meio ao curso normal das jornadas de trabalho e de tempo houvesse tempos de pausa. Trata-se de tradições sabáticas, que carregam consigo a temática do cuidado da vida. Referem-se ao sábado como dia de descanso, ao ano sabático para descanso da terra e para livre acesso aos frutos pelos pobres e pelos animais, bem como de perdão de dívidas. Na boca de Jesus de Nazaré, esta tradição ganhou a defesa mais contundente e mais conhecida, afirmando que o dia de sábado deve estar em função das pessoas e não o contrário. Nas tradições judaica e cristã trata-se de uma radical defesa do necessário cuidado com a vida, que poderia ser assumida hoje como heterotopia também em termos de espiritualidade.

Palavras-chave: Sábado. Descanso. Cuidado da vida. Espiritualidade. Pandemia.

\footnotetext{
a Universidade Estadual de Goiás (UEG), Anápolis, GO, Brasil. Doutor em Teologia, e-mail: haroldo.reimer@gmail.com. O artigo está vinculado ao projeto Religião e Natureza.

b Pontifícia Universidade Católica de Goiás (PUC Goiás), Goiânia, GO, Brasil. Doutora em Teologia/Ciências da Religião, e-mail: ivonirr@gmail.com
} 


\section{Abstract}

The context of the Sars-Covid pandemie gives the hermeneutical background for tis article concerned to biblical texts which recommend observing breaktimes within the worktimes. These texts emerged along the biblical times in the story of the ancient Hebrews with the goal that the people should observe breaktimes during the work processes. They are called as sabbatical traditions including the care for life. They concern the shabbat as a day of rest, the sabbatical year as a breaktime for the land as well as free access to the fruits of the fields by the poor and animal, and also as a year for the forgiveness of debts. Jesus of Nazareth has given the strongest defense of these tradition, saying that the shabbat shall exist for the people and not the people for the shabbat. In the Jewish and Christian tradition, it is a radical defense of the necessary care for the life, which should be assumed as a heterotopical perspective in terms of spirituality.

Keywords: Shabbat. Breaktimes. Care for life. Spirituality. Pandemic.

\section{Introdução}

Os anos de 2020-2021 ficarão marcados pelos próximos tempos como anos em que a pandemia da Covid-19 gerou rupturas no funcionamento das sociedades, em nível global, embora com diferentes graus de intensidade, a depender do sistema de saúde e da gerência da crise pelos governantes. Em termos econômicos, houve / há sérios abalos nas economias em seus fluxos financeiros e matriz de lucros. O produto interno bruto (PIB) global tem refluxo em várias casas percentuais e uma retomada será gradual, a depender do ritmo de imunização por meio de vacinas. Com o refluxo do crescimento econômico, as pessoas mais vulneráveis estarão mais expostas, e já há indicativos de que as sociedades se tornam ainda mais desiguais em face da pandemia. Em termos de vulnerabilidades sociais, destaca-se o aumento das várias formas de violência doméstica, especialmente contra mulheres, devido ao isolamento/distanciamento social e, portanto, à aglomeração de pessoas em espaço restrito e por tempo prolongado, aumentando o stress e a violência, bem como o ritmo de trabalho.

No escopo deste ensaio, pautado pelas reflexões acima apresentadas, o interesse está em colocar em análise alguns textos bíblicos que, há milênios, já projetavam utopias sobre tempos de pausa e descanso em meio ao (intenso) ritmo de trabalho como formas de cuidado com a vida. O itinerário do texto 
está assim pensado: num primeiro momento colocaremos em foco os textos bíblicos que tratam das tradições sabáticas, relativas a tempos de descanso, e, depois, agregaremos algumas reflexõs de cunho atual sobre o cuidado com a vida em meio a tempos turbulentos, tais como a Pandemia da Covid-19.

\section{Tempos de pausa como formas de cuidado com a vida na Bíblia}

As tradições bíblicas sobre os tempos de pausa estão etimológica e semanticamente relacionadas com o verbo hebraico shabat. Este verbo tem o significado básico de parar, cessar ou fazer cessar. Esse ato ou ação tem o sentido de resguardar ou cuidar a ou da vida, na medida em que implica no descanso da "alma" (hebraico: nefesh como o lugar/espaço pelo qual entra e sai a vida = a garganta).

Os tempos de pausa na Bíblia abarcam o dia de sábado, a tradição do ano sabático e também um ano jubilar, que se seguiria a um conjunto de 7 vezes 7 anos sabáticos. Desse conjunto podemos falar também de tradições jubilares. ${ }^{3}$ Aqui focaremos mais na tradição do descanso sabático.

\subsection{0 descanso sabático ${ }^{4}$}

Na sua origem, o shabat está relacionado com a organização do tempo de acordo com o calendário lunar, num ritmo de sete dias, passando-se a dedicar o sétimo dia como dia de descanso. No livro do profeta Amós há uma relação entre o sábado e a lua nova (Amós 8,4 ). Segundo os estudiosos, a menção mais antiga deste costume de fazer pausa, provavelmente do século IX a.C., encontra-se em Êxodo 34,21: "Seis dias trabalharás, mas/e ao sétimo dia pararás (= descansarás)", tanto no tempo do preparo da terra/semeadura

\footnotetext{
${ }^{3}$ Sobre isso ver Reimer e Richter Reimer (1999).

${ }^{4}$ Por ocasião do número 100 da Estudos Bíblicos, comemorando os 25 anos de existência desta revista bíblica pastoral, contribuímos com um estudo sobre o sábado sob o título "Sábado e vida digna" (Reimer e Richter Reimer, 2008, p. 79-93). Ver também Pixley (1999, p. 23-32). O texto em espanhol está disponível em: https://www.centrobiblicoquito.org/ribla/.
} 
quanto da colheita. Esse fragmento textual está inserido em uma pequena coleção de leis ou normas, que se costuma chamar de código ético ${ }^{5}$. Com o tempo, este dia de parada passou a ser designado pelo substantivo shabbat, sábado. Na tradição hebraica, o sétimo dia é dedicado ao descanso. Na tradição cristã, o descanso sabático foi transferido para o primeiro dia da semana, que na tradição latina recebeu o nome de dies dominus, ou domingo, em homenagem ao dia da ressurreição de Jesus Cristo. O descanso dominical foi, assim, transferido para o primeiro dia da jornada semanal de trabalho ou de tempo. A partir do século VIII, já na era cristã, os muçulmanos, para se diferenciar dos judeus e cristãos, adotaram o sexto dia como dia santo e de descanso.

Conforme está assentado na pesquisa, a tradição do descanso como cuidado da "alma" está relacionada com o mundo do trabalho. O termo “alma”, que é a tradução do hebraico nefesh, deve ser entendido em si como "garganta", como o lugar físico por onde entra e sai a vida 6 . O texto de Êxodo 34,21, referido acima, indica claramente para este ambiente do mundo do trabalho, o que é confirmado por outra menção, em Êxodo 23,12, provavelmente do século VIII a.C., que também estabelece a conexão com o trabalho. Ambos os textos se encontram dentro de coleções de leis e normas para o povo daquela época. Em Êxodo 34 encontra-se o "código ético" e em Êxodo 20,22-23,19, o “código da aliança”. O texto de Êxodo 23,12 indica muito claramente para os beneficiários privilegiados deste tempo de pausa: "para que descansem o teu boi e o teu jumento, e para que tomem alento o filho da tua serva e o estrangeiro / forasteiro". Em ambos os textos, os destinatários últimos da instituição da parada para descanso são os seres mais diretamente ativos e mais explorados na produção agrícola da época: animais de trabalho e servos. Os interlocutores, isto é, aqueles a quem os textos se dirigem estão indicados pela segunda pessoa do singular = "tu". Este "tu" são os donos da terra, provavelmente os pater familias, os chefes do clã familiar. O clã da época

\footnotetext{
${ }^{5}$ Sobre os diferentes códigos de leis no Antigo Testamento, ver Crüsemann (2001).

${ }^{6} \mathrm{O}$ termo hebraico nefesh, muitas vezes traduzido por "alma", designa mais especificamente a garganta, como o órgão do corpo pelo qual entra e sai a vida. Acerca do simbolismo da garganta ver Schroer e Staubli (2003, p. 77-90).
} 
do surgimento destes textos bíblicos abrigava servos/as e até trabalhadores de outros territórios, chamados aqui de ger = estrangeiros ou forasteiros, além, claro, dos familiares diretos, originados da relação com as várias mulheres que o patriarca poderia ter. Pode-se chamar esta unidade também de família patriarcal.

O pater familias era a figura gerenciadora desta unidade, responsável também pelo manejo econômico desta unidade de produção e reprodução familiar. Estima-se que estes dois textos, que tratam do descanso na relação com a exploração no trabalho, tenham surgido em composição de forças sociais como os levitas, sacerdotes e profetas, os quais procuravam orientar a vida das famílias e comunidades, emergindo, assim, como forças sociais de controle heterônomas em relação às famílias e clãs. Especialmente do ponto de vista profético, é muito contundente a crítica à exploração dos mais necessitados, vulneráveis ou pobres. Para isso basta ler alguns trechos de Amós, Miqueias ou Isaías (Amós 3; 5,10-12; Miqueias 3; Isaías 10,1-10)7. A crítica ao modo explorador de pessoas, animais e da terra provavelmente levou à geração de determinados consensos, formulados na forma de leis e normas como as acima referidas e que gradativamente foram reunidos em pequenas coleções, ao longo dos séculos, dando origem ao magnífico corpo de normas e novela histórica chamada de Torá ${ }^{8}$. Endereçadas aos chefes das famílias, as normas de descanso aqui em discussão implicavam em prováveis renúncias econômicas por parte das unidades familiares na medida em que os tempos de descanso ou de pausa interferiam nas práticas de trabalho continuado, quase em duro regime servil. Possibilitar o descanso implicava em perda econômica, mas permitia recobrar a "alma". O foco da norma está na vida das pessoas que mais diretamente estavam relacionadas com os ritmos de trabalho.

Além dos textos normativos acima referidos, o descanso sabático aparece também nas duas versões da coleção de normas chamada de Decálogo, em Êxodo 20 e Deuteronômio 5. Esta coleção provavelmente tem a ver com a atividade de levitas na época dos tempos bíblicos, no século VIII a.C.

\footnotetext{
7 Pode-se remeter ao texto com o título de "Profetas, pobres e defesa da dignidade" em Reimer (2017, p. 177-198). Um texto básico sobre os pobres na Bíblia e sobre o Direito dos pobres é a obra O Direito dos Pobres de Schwantes (2013).

${ }^{8}$ Sobre isso recomendamos a leitura da obra A Torá, de Frank Crüsemann (2001).
} 
Levitas eram, por assim dizer, sacerdotes menores itinerantes que atuavam junto às famílias. A coleção de dez normas provavelmente servia como um recurso mnemônico, para facilitar a memorização, visto que cada mandamento poderia ser associado com um dedo das mãos. Nas duas versões do descanso sabático no Decálogo encontram-se justificativas de ordem teológica, provavelmente já como um reforço para fazer valer a norma junto às autoridades patriarcais. Diferente em relação às tradições apontadas acima, aqui, em ambas versões, o shabbat já está referido a um proceso de santificação da pessoa e da comunidade. Em Êxodo 20,8-11, a justificativa teológica indica para o relato da criação, conforme apresentado em Gênesis 1. Os destinatários da norma continuam sendo os seres mais explorados no mundo do trabalho, mas o ponto de partida do descanso é a autoridade, o pai, indicado no texto como "tu". No seu descanso também se espelha o descanso do filho, da filha, do servo, da serva, do animal e do forasteiro. Este conjunto familiar, que deve se espelhar no comportamento do patriarca, é remetido ao comportamento de Deus enquanto criador. A estratégia do texto é mimética. O patriarca deve fazer como Deus fez, respeitando e fazendo respeitar o ritmo de tempo, adequado a ritmos de trabalho e pausa. A versão de Deuteronômio 5,12-15 mantém a mesma estrutura hierárquica, iniciando pelo descanso do patriarca, o que deve ter como consequência o descanso dos subordinados na unidade familiar. A justificativa teológica é feita com a tradição do êxodo, isto é, da milagrosa saída do povo de Israel do Egito. Aqui busca-se ativar a memória histórica. Deve-se respeitar e fazer respeitar o descanso, ativando a memória da escravidão dos antepassados sob o regime faraônico no Egito. Na história de Israel ou dos dois reinos de Israel e de Judá, tal realidade (quase) escravocrata provavelmente tinha suas atualizações na prática da corveia, isto é, do trabalho forçado em obras públicas ou na servidão em decorrência do empobrecimento familiar. Em todo caso, todos os textos que fazem referência ao descanso sabático, como refrigério para a "alma", além da justificativa teológica (teologia da criação e memória do êxodo), têm como foco principal o cuidado pela vida, e em especial a vida dos mais vulneráveis no ritmo e mundo do trabalho de então.

A maior densidade teológica do dia de descanso foi conferida pelo relato da criação em Gênesis 1,1-2,4. O referido relato serve como uma espécie de 
ouverture para toda a obra da Torá ou até mesmo da Obra Historiográfica Deuteronomista (Gênesis até 2 Reis). O texto está estruturado em linguagem mítica e busca apresentar para a comunidade de Israel, para aquele tempo e para os tempos futuros, um relato significativo para compreensão e estruturação da tradição do povo hebreu. Cabe registrar que tais relatos de criação são comuns entre os povos, marcando os respectivos relatos com especificidades de cada cultura. No caso da tradição judaica, por conta da herança dos textos pelo cristianismo e pela posição de oficialidade assumida por esta tradição no Império romano e depois nos impérios derivados, o relato bíblico ganhou status de texto verdadeiro9. A composição do texto de Gênesis 1 tem reconhecidamente traços e influências sacerdotais e uma vinculação umbilical com o templo de Jerusalém. A classe sacerdotal, que a partir do período persa (século V em diante) assumiu o comando da Província de Judá, deixou registradas as suas marcas teológicas. No conjunto da obra da Torá ou da Obra Historiográfica Deuteronomista há inequívocas marcas das pretensões e da realidade de domínio sacerdotal sobre a vida em geral da época, dentro dos contornos do antigo Israel. Assim, a observância do shabbat é uma espécie de pedra angular da tradição sacerdotal. Tal pretensão de controle social pelos sacerdotes pode e deve ser lida como o que foi: controle social, exercício de poder etc. Mas, nas contradições de toda instituição, há também elementos positivos, na medida em que no controle pela observância do sábado, sempre estavam incluídas as pessoas mais vulneráveis - embora nem sempre em primeiro plano. Vários textos que fazem referência ao shabbat (Jeremias 17,21-22; Isaías 56,2; Êxodo 31,1318; Êxodo 35,1-3; Levítico 19,3.30; 22,3; Neemias 10,31) reverberam as influências sacerdotais e reforçam o controle social para a observância da santidade deste dia.

Durante séculos certamente se travaram discussões, na tradição judaica, sobre a finalidade última desta proposta heterotópica de fazer pausas, de celebrar um shabbat em meio aos ritmos de trabalho e produção. A julgar

\footnotetext{
${ }^{9}$ Sobre as discussões acadêmicas referentes às noções de verdade ou lenda em mitos dos povos e mitos bíblicos, ver o texto "O mito como constituinte do imaginário" em Reimer (2017, p. 89-122). Lá também se encontram apontamentos sobre os momentos históricos de desqualificação do mito enquanto lenda ou invenção e seu recredenciamento a partir da antropologia na segunda metade do século XX.
} 
pelos textos logo acima referidos, acabou sendo uma espécie de mainstream a ideia de que era preciso defender e justificar a santidade do dia de descanso, por uma questão de comportamento mimético em relação ao agir divino no contexto da criação original (Gênesis 1). Essa discussão chegou ao tempo de Jesus, no século I. Os evangelhos sinóticos registram uma contenda entre Jesus e os fariseus em um dia de sábado. De forma prosaica, o texto de Marcos 2,23-28 (paralelo em Mateus 121,1-8 e Lucas 6,1-5) anota que estavam Jesus e os discípulos a atravessar algumas roças e, ao passarem, colhiam espigas. Este ato teria sido questionado por fariseus que, sabendo da santidade deste dia e sendo fiéis defensores desta proposta, inquiriam Jesus porquê ele e os discípulos faziam atividades que não eram lícitas para o dia de sábado. Neste contexto, Jesus expressa a sua percepção nos seguintes termos: "O sábado foi instituído por causa / em função do ser humano, e não o ser humano em função do sábado" (Marcos 2,27). Com este resumo interpretativo, Jesus enquanto rabino e intérprete da Torá/lei remete a tradição e a instituição do sábado ao seu contexto originário. A instituição da pausa sabática começou a existir em função do cuidado com as pessoas, especialmente as mais vulneráveis. Assim como alguns companheiros fariseus de sua época ${ }^{10}$, Jesus remete às origens o vir-a-ser do sábado como proposta para que as pessoas que mais trabalham e sofrem nos diferentes espaços produtivos possam ter a pausa para recompor a "alma". Para Jesus, não se trata de alimentar o capital simbólico-religioso do dia de descanso, mas efetivamente resgatar a sua funcionalidade em favor das pessoas que necessitam realmente do descanso, dessa pausa para recomposição da vida. Jesus foi uma das vozes dentro do judaísmo a manifestar a santidade deste dia com o sentido básico de cuidar da vida dos mais vulneráveis. Com Jesus e seus companheiros de fé e vida, talvez tenhamos de aprender a agregar perspectivas de cuidado com a vida, e não segregar tendências por questões ideológicas e/ou confessionais. Assim, a frase a seguir poderia ser de Jesus, mas é um comentário rabínico (apud REIMER; RICHTER REIMER, 1999, p. 53-54): “Toda vida que corre perigo é mais

10 Sobre vários textos e tradições farisaicas acerca do sábado e das 'transgressões' permitidas em benefício da vida ameaçada, no dia de sábado, ver Reimer e Richter Reimer (1999, p. 53-54). 
importante que o sábado; e se a dor de ouvido é um perigo, então ela dever ser curada no sábado".

\subsection{0 ano sabático}

A lógica do descanso sabático foi aplicada na tradição hebraica ao ciclo de sete anos, na medida em que deveria haver uma série de seis anos seguidos de um ano especial, no qual deveria haver um descanso para a terra e ações de perdão de dívidas. De saída já devemos deixar um alerta para o questionamento: trata-se somente de uma utopia? Ou funcionou heterotopicamente como uma proposta realizável no contexto da época?

É singular na Bíblia a pretensão de que deva haver um ano sabático para a terra. Convém neste caso apresentar o texto conforme Êxodo 23,10-11:

\footnotetext{
Seis anos semearás a tua terra e recolherás os frutos dela;

E no sétimo ano a deixarás descansar e não a cultivarás,

Para que os pobres do teu povo achem o que comer,

E do que sobrar comam os animais do campo.

Assim farás também com a tua vinha e com o teu olival.
}

Este fragmento textual está contido dentro do chamado código da aliança (Êxodo 20,22-23,19). A coleção de leis pode ter tido o seu surgimento no final do século VIII a.C. ou primeira metade do século VII a.C, visto que ecoa na forma de normas conciliadoras a crítica de profetas radicais que atuaram durante aquele século. A coleção toda tem o seu eixo programático na monolatria ao Deus Javé, uma tendência na vida religiosa do antigo Israel que passou a ganhar contornos de oficialidade com a chamada reforma de Ezequias (716-687 a.C.) e depois com a reforma de Josias (640-609 a.C.). Ambos os monarcas atuaram fortemente em prol da centralização do culto em Jerusalém e do culto somente a Javé, detratando publicamente outras expressões na vida religiosa do povo da época. Nos textos normativos do código da aliança há sempre um resguardo dos direitos dos mais fortes. No fragmento em questão, há um resguardo do direito dos fracos.

Afirmar um descanso intermitente para a terra de cultivo não é singular na história dos povos. A prática do pousio da terra ou da rotação de culturas, incluindo deixar intacta determinada área durante um ano, é conhecida entre 
povos tradicionais. Em geral, tal prática brota da consciência de que o ser humano está umbilicalmente relacionado com a terra. Na tradição bíblica, o humanus é afirmado como tendo sido originado do húmus, isto é, da terra fértil e não da argila ou do barro. É possível também que no antigo Israel tenha havido uma consciência do caráter sagrado da terra, em relação à qual é preciso reconhecer sua dimensão de fecundidade e fertilidade e, portanto, passível de ser resguardada para um descanso, assim como deve descansar a parturiente. A relação dessa consciência com cultos femininos é frequentemente afirmada na pesquisa.

Somente o conhecimento de ter havido ou de dever haver um descanso sabático para a terra já é digno de ser registrado e ser transmitido adiante. 0 possível ou provável descanso da terra de cultivo não nega a dimensão utilitária da exploração pelo ser humano. Porém, coloca-se um limita ao utilitarismo. O texto ainda vincula o descanso sabático da terra com uma finalidade social ou função social mais ampla. No sétimo ano os pobres do povo devem poder comer do que nascer livremente nos campos não cultivados. Certamente trata-se de pessoas em regime de servidão ou forasteiros que habitam na região. O texto, contudo, vai mais longe ao afirmar que o destino último do que crescer no ano de descanso da terra não são somente os humanos vulneráveis, mas também os animais do campo, que são incluídos na lógica jubilar. Quase como um acréscimo de reforço, o texto afirma que o ano sabático também deve valer para as culturas perenes: tanto vinhas quanto olivais deveriam estar abertos para saciar a fome de pessoas pobres e de animais. Para além deste tensionamento social quanto à sua real aplicabilidade, percebe-se no texto um insight ecológico que ultrapassa o viés meramente antropocêntrico e inclui terra, pessoas e animais dentro de um pensamento complexo. O cuidado com a vida vai além dos interesses dos humanos.

A tradição do ano sabático da terra é reverberada em Levíticos 25,1-7. O descanso sabático da terra deveria ser celebrado de forma solene, acompanhado com rituais litúrgicos, certamente operacionalizados por agentes vinculados ao templo central em Jerusalém. Esta tradição, no ritmo seis/sete anos, tem uma vertente mais social em normas e leis que tratam da libertação de pessoas que se tornaram endividadas ou entraram em regime de 
servidão junto ao credor. Essa tradição está novamente compilada em textos normativos.

No texto de Êxodo 21,2-11 afirma-se programaticamente que se um hebreu entrar no poder da mão de um credor, ele deverá ser alforriado no sétimo ano. Entrar no poder da mão de um credor ou senhor decorre em geral de relações de empréstimo de cereais por parte da pessoa pobre quando a sua terra não produz o suficiente para alimentar a família durante o ano. Várias são as razões que podem prejudicar a colheita num determinado ano: seca, ataque de gafanhotos, destruição por atividade bélica etc. Em tal situação, o hebreu camponês poderá recorrer a algum compatriota a fim de buscar socorro em termos de alimentos. Empréstimos de prata podem também ser necessários para pagamento de tributos junto ao templo ou corte real. O profeta Amós faz denúncia de que em tais relações de empréstimo também ocorriam fraudes nas balanças: colocava-se um fundo falso no recipiente para medir os grãos e se entortava o fiel da balança na hora de pesar a prata (Amós 8,4-7) 11. Quando se tornava difícil ou impossível devolver o cereal emprestado, o hebreu pobre poderia fazer a entrega de membros da família como pagamento de dívidas. Em geral, as filhas ou algum dos filhos eram entregues ao credor, tendo este assim a sua força produtiva ampliada, o que acentuava ainda mais as diferenças entre ricos e pobres. Quando o hebreu pobre não tinha mais recursos pessoais à disposição para quitar parte da dívida, impunha-se a decisão do próprio pater familias pobre se entregar à servidão. Isso tinha como consequência adicional a extinção de uma unidade familiar autônoma e a agregação das terras ao credor. Tais procedimentos são acompanhados criticamente, por exemplo, por reprovações proféticas, como registrado em Miquéias 2,1-4.

Tanto o texto de Êxodo 21,2-11 quanto o seu paralelo em Deuteronômio 15,12-18 procuram normatizar (ou propor a heterotopia) uma solução para tais situações que interferem diretamente no bem-estar da vida das pessoas pobres. Por um lado, a norma reconhece a instituição da escravidão por dívidas, sendo, assim, resultante da solução de conflitos sociais; por outro lado,

\footnotetext{
11 Sobre isso ver o capítulo "Formas de produção e relações econômicas e sociais" em Reimer (2017, p. 123-150), com indicação de leituras complementares sobre modo de produção na Antiguidade oriental.
} 
os textos propõem soluções ou saídas distintas conforme o gênero. $\mathrm{O}$ ano sabático teria plena validade para homens conforme Êxodo 21, mas não se aplicaria às mulheres que tenham sido entregues (ou vendidas) por conta de dívidas (Êxodo 21,7). Na tradição de Deuteronômio 15,12-15, a instituição sabática deve ter validade tanto para homens quanto para mulheres. $O$ credor é inclusive instado a exercer liberalidade, carregando os servos com bens da terra como um novo início para a vida em liberdade.

Como uma forma de prevenir as situações de escravização por dívidas, o texto de Deuteronômio 15,1-4 apresenta uma proposta de remissão de dívidas. No sétimo ano, o credor deveria remitir as dívidas, o que poderia significar concretamente quebrar publicamente as tabuinhas de argila em que constasse o registro de dívidas. A proposta tem um caráter interno aos hebreus, não tendo validade para os forasteiros ou estrangeiros.

\subsection{0 ano do jubileu}

O texto de Levítico 25,8-13 faz o registro de uma proposta de um ano jubilar ou ano de jubileu ${ }^{12}$. O nome deriva do termo hebraico jobel, que designa um chifre de carneiro utilizado como instrumento de sopro, uma espécie de berrante, para marcar o início de cerimônias sociais e religiosas (em Êxodo 19,13 usa-se o termo shofar). O ano jubilar deriva da multiplicação de sete anos sabáticos, devendo o ano seguinte, o quinquagésimo, ser celebrado como ano em que deveria haver um retorno dos israelitas para as suas terras originárias. Seria como uma espécie de anulação das relações de posse e propriedade exercidas e estabelecidas durante os 49 anos anteriores ao ano jubilar.

No Novo Testamento, essa tradição do ano jubilar aparece especificamente apenas em Lucas 4,19, numa citação de Levítico 25,10. As tradições do ano sabático de Êxodo 21 e 23 não reaparecem no NT, e a de Deuteronômio 15 apenas emergem indiretamente em Atos 4,34. Este dado é significativo para os estudos da obra lucana. Ele, o evangelista das nações e das pessoas mais vulnerabilizadas, entre elas, pobres, recorre a tradições de pousio e de prevenção de assimetrias sociais justamente em dois contextos

\footnotetext{
12 Ver Gass (1998); Garmus (1998); Reimer e Richter Reimer (1999); Richter Reimer (2004) e Silva (2016) para informações históricas e teológicas do ano sabático, com referências.
} 
fundantes para o movimento de Jesus e para a constituição ética de comunidades cristãs. Em Levítico 25,10, o tema do ano jubilar aparece junto com a liberdade da terra e de seus habitantes, bem como o retorno às suas propriedades e famílias.

Em Lucas 4,19, essa tradição do ano sabático (Levítico 25,10) é revisitada no contexto das relações estruturais político religiosas do império romano e sua ocupação de corpos da terra e de pessoas. Jesus, em sua interpretação dessas tradições sabáticas, se autoapresenta como realização "desta Escritura": no HOJE jesuânico transpira o tempo messiânico, em que práticas proféticas antigas são ressignificadas (Lucas 4,24-27) e vivenciadas por meio da práxis de Jesus. Significativa é a memória escriturística acessada para sua argumentação: Deus opera junto às pessoas necessitadas, independentemente de gênero, classe e etnia. O profeta Elias restaurou a vida da viúva pobre de Sarepta, Eliseu restaurou a vida do estrangeiro siro leproso Naamã. Ambos eram dupla e até triplamante discriminados: a viúva anônima, por causa de gênero, fome e etnia; Naamã, por causa de sua doença/impureza e etnia. Deus cuidou destas pessoas por meio de seus profetas.

Com a afirmação do HOJE para o cumprimento da profecia, incluso o ano jubilar, Jesus anuncia que sua praxis será realizada com base nessas tradições profético-terapêuticas. Esta "pregação inaugural” de Jesus em Nazaré não teve adesão de ninguém: "Todos na sinagoga, ouvindo estas cousas, se encheram de ira [...]", implicando esse anúncio de Jesus uma primeira reação negativa por parte de seus conterrâneos. Anunciada está, logo no início do evangelho de Lucas, a resistência à abertura de fronteiras, característica do movimento de Jesus, e a disposição de causar não apenas a sua expulsão de Nazaré, mas também a sua morte $(4,28-30)$. Com isso, indicase também para possíveis consequências de seu anúncio no campo político, visto que o ano sabático previa a devolução das terras ocupadas: o império romano estaria desafiado a desocupar a terra sagrada de Deus! ${ }^{13}$

\footnotetext{
${ }^{13}$ Acerca da terra santa ocupada e a sutileza argumentativa da resistência de Jesus, também no nível geopolítico e econômico, ver vários capítulos em Richter Reimer (2009) e Castro (2019).
} 
Em Atos 4,34, a tradição revisitada de Deuteronômio 15,4 evoca os cuidados com as pessoas mais vulnerabilizadas no conjunto da proposta de constituição das comunidades cristãs. A fé celebrada e vivida, fortalecida por ensino, oração e partilha de bens e saberes, possibilita a construção de relações que protegem as pessoas frente às realidades de empobrecimento e abandono no contexto do império romano. A unidade se realiza na diversidade de carismas espirituais e sociais, no objetivo de prevenir qualquer tipo de necessidade, especificamente financeira, garantindo subsistência digna a cada membro.

Parece, portanto, que no contexto neotestamentário, as tradições sabáticas eram conhecidas e em parte observadas entre pessoas judias e judeu-cristãs. Em todo caso, Jesus e seu grupo conheciam e viviam os seus enunciados, sendo que essa vivência foi questionada por alguns de outros grupos (p. ex. Lucas 6,1-5.6-11; 13,10-17; 14,1-6). Contudo, no que se refere às recepções das tradições no Novo Testamento, as tradições do ano sabático foram relegadas praticamente ao esquecimento, visto que, via memória e releitura, elas aparecem explicitamente apenas uma vez, como abordado acima.

\section{Cuidar da vida com tempos de pausa}

Do contexto das reflexões de uma Escola de Enfermagem, tomamos a liberdade de inserir a seguinte citação orientadora de Maria Gaby Rivero de Gutiérrez (2005, s/p):

O cuidado com a vida está a exigir de nós uma reflexão sobre a condução que temos dado ao tempo que dispomos e sobre as prioridades que temos estabelecido entre as várias coisas que precisamos e desejamos fazer. Urge que aprendamos a conjugar as duas maneiras de viver o tempo - "o que é medido pelas batidas do relógio e o que é medido pelas batidas do coração".

É reconhecido na atualidade que o ritmo de trabalho e exploração da vida e dos recursos da Terra está acelerado, gerando diversas formas de adoecimento. A pandemia da Covid-19 pode ser uma das respostas do ambiente maior a essa incessante marcha da comunidade humana sobre a Terra e seus recursos. 
Os estudiosos das coisas da vida e da ciência afirmam que nestes tempos de pandemia há uma confluência de três crises distintas, as quais estariam intrinsicamente ligadas entre si. Estas três crises são: a) a questão das mudanças climáticas, b) a destruição crescente da biodiversidade e c) o adoecimento coletivo dos organismos, especialmente por intoxicação química industrial ${ }^{14}$. Com base nestas reflexões e estudos podemos aqui pontuar algumas questões.

Sobre o tema das mudanças climáticas há um reconhecimento de que as emissões de gases por conta da intensa atividade industrial e agropastoril geram gradativamente um aquecimento global, em decorrência do efeito estufa, com capacidade para forçar a (re)adaptação de animais, plantas e pessoas em novos espaços ou nos espaços existentes. Por exemplo, o avanço do desmatamento na Amazônia influencia, e negativamente, o ciclo de chuvas no Centro-Oeste, o que deve interferir nas áreas de cultivo agrícola nas próximas décadas. As várias ou muitas conferências promovidas pela Organização das Nações Unidas (ONU) procuram estabelecer entre os países acordos quanto à diminuição ou os limites dessas emissões de gases poluentes. Pelo Acordo de Paris, firmado entre 195 países em 2015, o ano de 2020 deveria ser a ponta da curva, devendo se seguir um achatamento dos níveis de emissões. Aparentemente, não foram alcançados resultados significativos neste sentido. Com o advento da pandemia da Covid-19, contudo, a humanidade está sendo forçada a um tempo de menor intensidade consumista e, com isso, de menor ataque sobre os recursos naturais e com menor emissão de poluentes, o que provavelmente será algo passageiro, a ser superado com a retomada econômica pós pandemia. No entanto, o que a racionalidade das negociações entre as nações não conseguiu reverter ou alcançar, a pandemia vai impondo forçosamente, o que Boaventura de Sousa

\footnotetext{
${ }^{14}$ Sobre isso vale a pena ler o artigo do professor Luiz Marques, da Unicamp "A pandemia incide no ano mais importante da história da humanidade. Serão as próximas zoonoses gestadas no Brasil?". Acesso em 05 de maio de 2020. Disponível em: https://www.unicamp.br/unicamp/noticias/2020/05/05/pandemia-incide-no-ano-maisimportante-da-historia-da-humanidade-serao-proximas?fbclid=IwAR3PyOrCKbqDbVbcv1SObkbGBPUNWCPG-qIc9fi4fIU5OEiVeT3zHIDZKE
} 
Santos (2020) chamou de "cruel pedagogia do vírus". Este, portanto, poderia ser um tempo de reflexão mais profunda em termos pessoais e coletivos sobre o que realmente é preciso para o bem-viver de todos os seres.

Com os acelerados ritmos de produção e consumo capitalista, dentro do paradigma moderno de vetente industrial, os recursos naturais, já entendidos como finitos, vão sendo gradativamente exauridos. A técnica moderna, auxiliar em muitos sentidos, provoca, no fundo, uma subjugação dos recursos naturais aos interesses capitalistas. Pelo comportamento consumista coletivo, participamos, enquanto indivíduos e coletividade, da devastação coletiva do planeta com intensa destruição da biodiversidade, em nível local e global.

Hoje já está suficientemente demonstrado que a voracidade consumista, tanto capitalista quanto dos antigos regimes socialistas, dentro da lógica industrial e da falta de cuidado com o ambiente, avança sobre a biodiversidade global na mesma proporção do aumento da população mundial. Alguns cientistas até propõem designar os últimos dois séculos após a revolução industrial de "antropoceno", como sendo uma nova era geológica, com a característica principal de que a comunidade humana interfere no ambiente global em decorrência do seu estilo de vida devastador do ambiente (TORRES, 2017). No mesmo ritmo das devastações ambientais, verifica-se também um gradativo aumento da temperatura do planeta, chamado de aquecimento global. Mesmo sendo negado por pessoas de vertente terraplanista, o aquecimento exige a readaptação de plantas, animais e seres humanos a novas temperaturas, o que causa sérios distúrbios nos ecossistemas arranjados ao longo de séculos ou milênios. O pesquisador Aaron Bernstein, que na Universidade de Harvard coordena o Centro Clima, Saúde e Desenvolvimento global, sintetiza a interação entre aquecimento global e desmatamento como prováveis fontes ou focos para novas pandemias nos seguintes termos:

À medida que o planeta se aquece [...] os animais deslocam-se para os polos fugindo do calor. Animais estão entrando em contato com animais com os quais eles normalmente não interagiriam, e isso cria uma oportunidade para patógenos encontrar outros hospedeiros. Muitas das causas primárias das mudanças climáticas também aumentam 0 risco de pandemias. 0 desmatamento, causado em geral pela agropecuária é a causa maior da perda de habitat no mundo todo. E essa perda força os animais a migrarem e potencialmente a entrar em contato com outros animais ou pessoas e 
compartilhar seus germes. Grandes fazendas de gado também servem como uma fonte para a passagem de infecções de animais para pessoas (MARQUES, 2020, s/p).

Já está demonstrado que a forma de organização moderna, capitalista e consumista da comunidade humana global é responsável por surtos pandêmicos como a Covid-19 e outros que possam vir a surgir. É como se a natureza reagisse de forma auto-organizativa às incessantes investidas dos humanos sobre ela. O teólogo franciscano Leonardo Boff (2020, s/p) sintetiza bem esse ponto de vista ao dizer que o Corona vírus é uma "resposta do planeta":

Nunca ofendemos e agredimos tanto a mãe terra como nos últimos séculos. Agora chegou um ponto em que ela diz "Basta! Não aguento mais!". E ela mandou os petardos dela. Contra atacou. O coronavírus é uma resposta à nossa agressão. O vírus é uma reação da natureza. Porque nós movemos durante séculos uma guerra contra ela. Nós não temos nenhuma chance de ganhar essa guerra. Nós podemos desaparecer, a terra vai continuar girando em volta do sol por milênios.

Em face desta realidade, há diferentes posturas que se pode adotar. A tendência geral das pessoas poderá ser a indiferença com tais questões, desde que se consiga encontrar uma forma de continuar navegando para sobreviver. Para outras pessoas, sintonizadas com os sinais dos tempos, e atentas aos sinais, deve-se procurar ou construir alternativas para que o cuidado com a vida seja também um cuidado com o ambiente ou a natureza.

Já são significativas as práticas de produção de alimentos saudáveis por meio da agroecologia em suas muitas variantes. A economia solidária, de matriz cooperativista e/ou associativista, também apresenta seus resultados. Mudanças legais para a produção de energia limpa, de fonte renovável, também constituem contribuição gradativamente importante. Do ponto de vista do imaginário e das representações, importa manter vivas ou ressignificar tradições de diferentes povos que testemunham acerca de uma relação mais saudável consigo mesmo e com o ambiente ou natureza. Neste sentido, traz à memoria as tradições bíblicas sobre o descanso sabático com um cuidado com a vida pode ajudar a empoderar iniciativas e povos imaginários e espiritualidades ou eco-espiritualidades. 
Nos espaços em que vigora maior sensatez, a pandemia tem servido como tempo de pausa para cuidar da vida, mesmo em detrimento da economia. Onde os líderes e autoridades propõem procedimentos de cuidado e zelo, as vidas foram mais zeladas e poupadas. Em nosso contexto brasileiro, contudo, não tem sido assim. Isso apresenta uma razão adicional para a reflexão sobre a necessidade de tempos de pausa. O progresso com suas técnicas cada vez mais aprimoradas muitas vezes se torna cego e surdo às demandas da vida, negando a necessidade da sustentabilidade e do cuidado da vida como pontos angulares da existência conjunta sobre o planeta.

O cuidado com a vida e os tempos de pausa podem ser construídos como uma alternativa em meio aos ritmos intensos de trabalho e da ciranda capitalista. Com palavras sábias ensina Edgar Morin (MORIN; HAIDT, 2020, s/p):

\footnotetext{
Antes, a gente achava que existia um progresso certo e agora o futuro é uma angústia. Por isso, suportar, enfrentar a incerteza é não naufragar na angústia, saber que é preciso, de certa forma, participar com o outro, de algo em comum, porque a única resposta aos que têm a angústia de morrer é o amor e a vida em comum.
}

Um tempo de pausa no contexto do isolamento talvez seja até mais difícil do que em outros tempos, em que tudo parecia "normal", até porque nesses tempos muita gente não quis e não quer parar, mas há de se cuidar para não confundir pausa e isolamento. Mesmo que tenham alguns aspectos em comum, como a mudança de rotina, uma menor circulação de pessoas em espaços públicos e, portanto, uma maior permanência em espaços privados/domésticos, o isolamento não fez com que se produzisse menos nas monoculturas do agronegócio e na agropecuária e, simultaneamente, também não contribuiu para com a maior produção de alimento para a maioria da população. O resultado disto é mais pesticidas no ar, na terra, nas águas, nos alimentos... O isolamento tem aumentado ou melhor visibilizado as diferenças sociais e econômicas, porque as partes mais vulnerabilizadas não tinham um fundo emergencial ao qual pudessem recorrer para suprir necesidades emergenciais, e a pobreza e a fome aumentaram, desvelando e aprofundando o abismo das desigualdades. $O$ isolamento não tem diminuído as tantas formas de violência, em destaque a violência doméstica, bem como as matanças nas periferias das cidades ou o descaso com povos indígenas... 
As diferenças entre isolamento e pausa continuam marcantes. A pausa e o pousio bíblicos propõem um tempo de deixar respirar, descansar, recompor energias, refletir e transformar profundamente o modo de viver e, com isto, também inspirar. O pousio e a pausa andam de mãos dadas com o cuidado, a prevenção e o fortalecimento das imunidades em todos os seres, também da terra, querem recriar vida ali onde a morte já passava a vigorar: refazer ambientes e condições vitais, refletir e celebrar a vida, revitalizar solidariedade, restaurar relações e "dar um tempo" para aquilo que já não tinha mais sentido. Refazer, fazer diferente... esta talvez seja a proposta mais necessária e convincente para a vida nesses tempos de pandemia e no vindouro pós-pandemia. O “novo normal” haverá de ser qualitativamente diferente, ou levará todo mundo para ao abismo, e haverá muito mais choro e ranger de dentes do que já há... As perspectivas políticas, pessoais e coletivas, são de seleção de prioridades para a vida construível em relações de menos desigualdades e de mais cuidado com as partes mais vulnerabilizadas (1Coríntios 12). Este é o grande desafio dos "tempos de graça” na sua forma de convocação à pausa em meio às desgraças presentes e vindouras. E é neste limiar que se mesclam as linguagens bíblicas profética, legal e apocalíptica, num esforço recriado de buscar persuadir e fazer crer que é possível e urgentemente necessário fazer diferente e marcar a diferença.

\section{Considerações finais}

Neste texto buscamos retomar o tema de tradições bíblicas sobre tempos de pausa. Trata-se de variantes de tempos de graça, tempos sabáticos, tempos jubilares... tempos revisitados no contexto da pandemia da Covid-19 e do recrudescimento das violências cometidas contra o ambiente e contra uma maioria de pessoas em nível local e global.

Tempos de pausa são uma herança antiga, que emergiu do judaísmo antigo, está inscrita nas páginas do Primeiro Testamento e presente também em alguns textos no Novo Testamento, retomados para análise reflexiva. São tradições sabáticas que têm origem no sofrimento do povo trabalhador empobrecido e na exploração da terra, ambos cansados. Trata-se de tradições legais com aportes proféticos, e esta legislação visa restaurar vida digna para 
todos os seres por meio do descanso, do acesso aos frutos do trabalho, da redistribuição da terra e do perdão de dívidas. No Novo Testamento, esta tradição legal mescla-se com fragmentos de profecia e é recriada no movimento de Jesus e em primeiras comunidades cristãs. Esta proposta enfrentou e continuará enfrentando adesão e oposição por causa da sua radical alternativa em relação aos modos e sistemas de produzir e consumir de todos os tempos.

Por isto mesmo é que se tornou mais relevante e atual revisitar estas tradições para o nosso tempo, marcado não apenas pela pandemia da Covid19, mas por necropolíticas e necroeconomias de ganância, hipocrisia, acúmulo e equívocos. Fazer pausa em termos sabáticos é anunciar um novo tempo de partilha, solidariedade ecodiaconal, misericórdia, portanto, uma profunda mudança de mentalidade, conversão que tem o cuidado com a vida como diferencial e referencial. Em Jesus, esta proposta faz parte da espiritualidade que coloca a vida, os dons e o "sábado"-lei a serviço da vida plena de todos os seres. Isto continua sendo desafio atual e pode ser reinventado com criativa e responsável inteligência a partir das atuais condições e possibilidades que ciências e tecnologias podem oferecer e promover em função da sustentabilidade. Para tal, também se faz necessária uma política inteligente e competente. A exemplo de Jesus e seu movimento, a espiritualidade sabática permeará todas as dimensões, desde o planejamento estratégico até a sua realização, mantendo o foco no cuidado da vida.

\section{Referências}

BOFF, L. "Coronavírus é uma resposta do planeta". In: Brasil de Fato, 2020. Disponível em: https://www.brasildefato.com.br/2020/06/20/leonardo-boff-coronavirus-e-umaresposta-do-planeta. Acesso em: 20 out. 2020.

CASTRO, H. Devolvei a César o que pertence a César: a vida incômoda de um camponês galileu frente a Roma. São Paulo: Fonte Editorial, 2019.

CRÜSEMANN, F. A Torá. Teologia e história social da lei do Antigo Testamento. Trad. Haroldo Reimer. Petrópolis: Vozes, 2001.

GARMUS, L. O descanso da terra: uma releitura de Êx 23,10-22 e Lv 25,1-7. Estudos Bíblicos, Petrópolis, n. 58, p. 98-115, 1998. 
GASS, I. B. O ano do jubileu, um ano de libertação: Lv 25. Estudos Bíblicos, Petrópolis; São Leopoldo, n. 57, p. 9-23, 1998.

MARQUES, L. "A pandemia incide no ano mais importante da história da humanidade. Serão as próximas zoonoses gestadas no Brasil?". Disponível em: https://www.unicamp.br/unicamp/noticias/2020/05/05/pandemia-incide-no-anomais-importante-da-historia-da-humanidade-seraoproximas?fbclid=IwAR3PyorCKbqDbVb-cv1SObkbGBPUNWCPGqlc9fi4flU5OEiVeT3zHIDZKE. Acesso em: 05 maio 2020.

MORIN, E.; HAIDT, J. Lições da pandemia: o despertar para as grandes verdades humanas. Fronteiras do Pensamento, 2020. s/p. Disponível em: https://www.fronteiras.com/artigos/licoes-da-pandemia-o-despertar-para-asgrandes-verdades-humanas. Acesso em: 04 ago. 2020.

PIXLEY, J. O sábado: festa e sinal. Revista de Interpretação Bíblica Latino-Americana, Petrópolis, n. 33, p. 23-32, 1999.

REIMER, H. O antigo Israel. História, textos e representações. São Paulo: Fonte Editorial; Anápolis: Editora da UEG, 2017.

REIMER, H.; RICHTER REIMER, I. Tempos de graça. O jubileu e as tradições jubilares na Bíblia. São Leopoldo: CEBl; Sinodal; São Paulo: Paulus, 1999.

REIMER, H.; RICHTER REIMER, I. Sábado e vida digna. Estudos Bíblicos, Petrópolis, n. 100, p. 79-92, 2008.

RICHTER REIMER, I. Construção de Heterotopias socioculturais nas origens de comunidades judaico-cristãs. Caminhos, Goiânia, v. 2, n. 1, p. 113-122, 2004.

RICHTER REIMER, I. (org.). Economia no mundo bíblico: enfoques sociais, históricos e teológicos. São Leopoldo: Sinodal; CEBI, 2006.

RIVERO DE GUTIÉRREZ, M. G. O cuidado com a vida. Revista da Escola de Enfermagem da USP, São Paulo, v. 39, n. 3, editorial, 2005. Disponível em: https://www.scielo.br/scielo.php?script=sci_arttext\&pid=Soo80-

62342005000300001. Acesso em: 20 mar. 2021.

SCHROER, S.; STAUBLI, T. Simbolismo do Corpo na Bíblia. Trad. Paulo Ferreira Valério. São Paulo: Paulinas, 2003.

SCHWANTES, M. O Direito dos Pobres. São Leopoldo; São Bernardo do Campo: Oikos; Editeo, 2013.

SILVA, V. Direito à terra, direito à vida: Perspectivas ecológica a partir de Levítico 25. Fragmentos de cultura, Goiânia, v. 26, n. 4, p. 596-606, out./dez. 2016. 
SOUSA SANTOS, B. A cruel pedagogía do virus. Coimbra: Almedina, 2020.

TORRES, S. O antropoceno e a antropo-cena pós-humana: narrativas de catástrofe e contaminação. Tropos pós-humanos na literatura contemporânea, Ilha Desterro, v. 70, n. 2, ago. 2017. DOI https://doi.org/10.5007/2175-8026.2017v70n2p93

RECEBIDO: $18 / 05 / 2021$

RECEIVED: 05/18/2021

APROVADO: 09/09/2021

APPROVED: 09/09/2021 